\title{
Paideusis
}

\section{Knowing Sex: Formal and Informal Sex Education}

\section{Priscilla Murray}

Volume 9, Number 2, 1996

URI: https://id.erudit.org/iderudit/1073243ar

DOI: https://doi.org/10.7202/1073243ar

See table of contents

Publisher(s)

Canadian Philosophy of Education Society

ISSN

0838-4517 (print)

1916-0348 (digital)

Explore this journal

Cite this article

Murray, P. (1996). Knowing Sex: Formal and Informal Sex Education. Paideusis, 9(2), 21-32. https://doi.org/10.7202/1073243ar

(c) Priscilla Murray, 1996

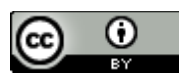

This document is protected by copyright law. Use of the services of Érudit (including reproduction) is subject to its terms and conditions, which can be viewed online.

https://apropos.erudit.org/en/users/policy-on-use/
This article is disseminated and preserved by Érudit.

Érudit is a non-profit inter-university consortium of the Université de Montréal, Université Laval, and the Université du Québec à Montréal. Its mission is to promote and disseminate research.

https://www.erudit.org/en/ 


\title{
Knowing Sex: Formal and Informal Sex Education
}

\author{
Priscilla Murray, Mount St. Vincent University
}

\section{Do I have a good sex life?}

When I was a high school student, I was asked to complete a personality profile as part of a selection process which was to choose delegates to represent Canada at an international youth conference. For each of the many statements in the questionnaire, a number was to be given to indicate a response from "strongly agree" to "strongly disagree." It was a psychological test used in industry at the time to assess employee attitude and many of the questions were inappropriate or irrelevant for high school students. In the whole test, the statement with which I had the most difficulty was the one which read "I have a good sex life." If I agreed, which is what I wanted to do, for I was happy in my body and in my relationships, I wondered what that would be considered to be saying from "their" point of view. Would it mean to the readers that I was sexually active or very active? On the other hand, if I disagreed because I was not sexually active at that time, I wondered what that would convey. Would it be interpreted as a sign of unhappiness or would it raise a question of abuse? I pondered this question for a long time and it has interested me ever since.

What does this question "Do I bave a good sex life?" ask? Clearly, it is not only a question of whether I am free of any sexually transmitted disease or whether I am able to prevent an unwanted pregnancy, nor can it be answered by a quantitative review of the number and intensity of my orgasms. But what else does it involve? Does it ask whether I am happy with my own sexuality? Or, is it a question about what kind of sexual activities I engage in or do not engage in? Can this question be answered without a consideration of my sexual relationships? Does it not also raise the question of "Do we have a good sex life?"'? And who does that include? Clearly, it must involve the ones who are closest to me, but my sex life or our sex life is not unrelated to the sex life of the society in which we live. Do we, as a society, have a good sex life? What is our sexual reality? How is it shaped and how does it shape our lives? What are our possibilities, individually and collectively, with respect to it?

While many individuals in our society have a good sex life, many do not. Violence and alienation characterize many sexual relations in modern western society. Rape, sexual assault, the sexual abuse of women and children, and, in a similar but less obvious way, sexual harassment are all forms of sexual coercion. These forms of violence always inflict emotional damage as well as physical hurt. Pornography and prostitution, which commercialize sexuality and sexual violence, make use of sexual oppression for profit. Advertisers, who use sexual images in order to sell merchandise, manipulate our sexual responses for their own purposes. Within the context of a capitalistic and free enterprise economic system, the commodification of sex, women, and women's bodies, is both a cause and a result of the objectification of sex, of women and of their bodies. This objectification is expressed in the way women's bodies, and increasingly men's bodies, and body parts are displayed, eroticized, and manipulated in advertising. Publicity succeeds by persuading us to buy and, therefore, competition for consumer attention results in the use of more and more blatantly sen- 
sational images in order to attract notice. As we become accustomed to sensational images, more violent or more sexually explicit material is used to gain our attention. Because sex is associated with the most intimate experiences of our lives and violence is related to our deepest fears, images of, and references to, these cannot be ignored. For this reason, sex, violence, and violent sexuality sell, and the images which are presented shape our notions of sexuality, exciting sex, and good sex. It becomes increasingly difficult to define the difference between pornography and advertising, between pornography and films (or television programming) for the general public since sexual innuendo and explicit sexual portrayal, often with suggestions of violence, pervade the media. Each of us is influenced by this context of violence and sexual display.

Sexual violence expresses anger and results in feelings of alienation. It is primarily perpetrated by men on women although sometimes the victims are children. The asymmetric power relationship between men and women, built upon the patriarchal understanding that women are for men, is supported by, and reflected in, stereotypical images of men as powerful and women as seductive. In this relationship, the possibility of violence is always present. Sexual violence reveals and constructs relations of domination and subordination between males and females in the society and is an issue for both males and females. These kinds of relationships which affect our understanding of sexuality and our lives exist not only between males and females but also among males and among females. The association of violence with sex eroticizes relationships of domination and submission and perpetuates the cycle of rape, sexual abuse, pornography, and sexual violence. Sexual violence and the commodification of sex, women and bodies provide evidence of a widespread depersonalization of sex. An emphasis on sexual gratification and sexual conquest unconnected to caring relationships is related to experiences of isolation and loneliness, yet these kinds of sexual relationships are commonly presented and glorified in the media.

What is a good sex life and what is the present reality for us as individuals and as a society? How can we move from the present situation towards a better one? If we see what the situation is, how it might be improved, and how a movement in that direction could be achieved, change is possible. Education provides a vehicle for this change. The belief that we can intentionally produce desirable changes is the fundamental belief of formal education. This may be accomplished either by introducing students to new experiences and new information which will augment earlier and perhaps inadequate learning and, thereby, change their situation or by teaching students to reflect upon their situation so that they can actively intervene in the ongoing processes which constitute their lives.

Educators must be concerned with the methods and technical details required to ensure that the goals which have been assumed or established can be reached, but an ongoing assessment of the situation and an evaluation of the aims are also required. At the same time, educators also need to develop the students' ability to raise these kinds of questions for themselves, so that the inquiry about what the situation is, what a good life might be, and how this might be realized can be continued.

Formal sex education is concerned with the communication of material which is intended to convey information about sex, to develop an understanding 
of sexual ideas and practices and of sexual relationships, to foster certain attitudes about sex, to question our established ideas and practices, and to allow discussion of issues related to sex. It responds to the question "What do we need to know about sex?" However, this question can only be answered with reference to the knowledge about sex which we already have. ${ }^{1}$ In our cultural situation, it requires an examination of the socially constructed understandings of sexuality and the ways these have been shaped and are conveyed-that is, it requires an understanding of the informal education which the students and the teachers have had. Since formal sex education involves an intention to educate, the questions "What is the aim?", "How is it best accomplished?" and "Who has decided?" are always relevant for, in choosing goals and methods and in implementing programmes, we become responsible for their consequences.

\section{Learning sex}

The word "sex" refers both to the category of gender and to erotic relationships and their physical expression; it refers to who we are and what we do. Our sexuality is expressed in the ways we are related to ourselves and to others, male or female, through our bodies. It is as general as this statement suggests - since we are embodied, gendered, and social creatures, we are sexual and our sexuality pervades our lives-but it is also more specific, referring to intimate passionate relationships, acts of reproduction, and erotic expression. These two aspects of sexual- ity - which refer to ourselves naked and ourselves clothed-are dialectically related. Beliefs and practices with respect to our more intimate sexual relationships affect the way we think about and behave in all our other relationships, and vice versa.

Our sexual experiences are among the most personal, intimate, ambiguous, and individual of experiences: they are related to body, desires, and our sense of self. Sexual experiences are related to pleasure and danger, to desire and fear. We have the possibility of finding and expressing delight through physical and emotional intimacy or of expressing and finding anger and feelings of despair and degradation. Our sexuality is expressed in relationships which bring us closer to one another or which reveal and increase our isolation and our separation from one another. The highest forms of love and the most violent and depraved forms of hatred have been expressed in sexual relationships and yet there are sexual relationships which seem to have no emotional component. Sexual relationships may result in new life and, therefore, sexuality is related to the wish to have children and to the social, economic, and moral responsibility of having children, yet sexual activity is not limited to reproductive acts. And although the birth of a child has implications for the individuals involved, the growth of the population has economic and social consequences for the local and the global community. The sexuality of individuals is personal but sexual relationships are also of public concern. Every society has organized and regulated erotic life, although there is an immense variety in the expression of sexuality and the understanding of it in different contexts. And sexuality is observed, discussed, and disciplined by legal, educational, medical, religious, social, and political institutions in every society.

Our sexuality, both personal and cultural, is a product of the complex interplay of individual, social, and historical forces. As Jeffrey Weeks has emphasized: 
[Our sexuality] is a result of diverse social practices that give meaning to human activities, of social definitions and self-definitions, of struggles between those who have power to define and regulate, and those who resist. Sexuality is not given; it is a product of negotiation, struggle and human agency. (Weeks, 1986, p. 25)

Our understandings of sex are expressed publicly in and conveyed by "moral treatises, laws, educational practices, psychological theories, medical definitions, social rituals, pornographic and romantic fiction, popular music and commonplace assumptions"' (Weeks, 1986, p.16). Physical expressions of sexuality are individual and unique, but they take place and are understood in relation to the particular context in which the individual lives and in relation to the cultural assumptions, customs, and values.

Sexuality, like gender, is socially constructed. We learn about sex and sexuality in our social settings beginning in early childhood. We learn how to behave, what to believe, and what is expected of us within a social and historical context. Although there is a shared social reality for individuals at a particular time and in a particular place, each one is situated uniquely in that reality. In a sex education programme, the teacher needs to take account of the experiential knowledge students bring with them. All students, for example, will have had experiences which influence their understandings of gender, their attitudes about their body, and their feelings of self-esteem. Students who have been sexually abused or who have been in physically or emotionally abusive relationships will know about sex differently than those who have been affirmed and loved in the home and by their friends and lovers. Students who have been sexually active will have a different knowledge base than students who have not; yet in either case, they are sexual persons with sexual knowledge. The experiential knowledge is different from knowledge which is information about sexual matters, such as that the consistent and correct use of condoms can prevent unwanted pregnancy and the transmission of sexually transmitted disease.

Teachers should be aware that the way they treat students in the class is the aspect of the sex education class which is closest to an experiential learning about sex. Although they are not part of a formal curriculum, the relationships and experiences with others inside and outside the classroom shape students' understandings of themselves, of relationships, and of possibilities as much as or more than the ideas which are discussed,

\section{Knowing sex}

The curriculum of a formal sex education programme responds to the question "What do we need to know about sex?" and identifies topics and approaches which may help students to know about, understand, and reflect upon issues of sexuality. However, because there are many different kinds of questions which are related to different kinds of knowledge, which cannot all be answered in the same way, it is useful to examine our knowledge of ourselves, others, and the world and, therefore, our knowledge of sexuality in relation to different categories of knowledge. Empirical, social, critical, and ethical forms of knowledge correspond and respond to different human interests and concerns. These four categories of knowledge are not the only kinds of knowledge that we might have, nor is this classification the only way that knowledge could be analyzed, but the discussion of knowledge in these terms provides a framework 
for questioning and examining the knowledge which shapes our lives and it provides a framework in relation to which educators, and more specifically sex educators, can think about and evaluate curriculum. These four categories of knowledge or processes of inquiry establish and reveal different kinds of relationships with the world. They function differently and they serve different human purposes although they are related to one another and operate together and they cannot in practice be separated.

In the most simplistic formulations, an empirical inquiry asks "How can we do what we wish?"; a social inquiry raises the questions "What do you mean?" and "Who are we?"; and an ethical inquiry wonders "What should we do?" and "How shall we make our choices?" A more reflective, critical inquiry examines the assumptions and the political relationships which have produced the social reality in which we live and asks "Why were these choices made?" All of these forms of knowledge can operate together in the formulation of plans for action which can be based upon a realistic assessment of the situation and a knowledge of the forces which have produced it. At best, our intentions are informed by a recognition of our responsibility for the decisions we make, for the consequences of our actions, and by understanding that the well-being of individuals cannot be separated from the well-being of the society.

Empirical knowledge of sex has an important function. Questions about processes, about the results of actions, about how to ensure desired ends, or how to prevent unwanted outcomes are empirical inquiries. Empirical knowledge conveys a power related to the possibility of control over events, and it is, therefore, a kind of knowledge which we wish to cultivate. Empirical information and technical skills are needed so that students can learn how to protect themselves from unwanted pregnancies and from sexually transmitted disease. As adolescents enter puberty, it is often felt that it is useful for them to know about the changes in their bodies which will take place, learn about the human reproductive systems, and understand the wide range of physiological variation among individuals. The study of sexual anatomy, which some sex educators have called the plumbing part of the programme, constitutes the largest component of many sex education programmes, although many students do not feel that it is very useful. Bonnie Trudell quotes a student commenting on a sex education course: “Just the stuff you had to know, I don't know if we'll ever use it" (1992, p. 211). Physical development takes place whether or not the processes are understood!

During adolescence, individuals become sexually mature. Many adolescents engage in sexual activities (King, 1989; Bibby \& Posterski, 1992). However, unprotected sexual activity has resulted in too many unwanted pregnancies and sexually transmitted diseases among young people. Canadian youth have been identified as potentially at risk for HIV infection (King, 1989, p. 5) through unprotected sexual intercourse. The goals of sex education have been urgently defined in relation to these facts. In order to decrease the occurrence of the negative consequences of early sexual activity, sex education programmes are supported by all levels of government and within the community. The report of the Federal/Provincial/Territorial Working Group on Adolescent Reproductive Health recommends "that provincial and territorial health departments advocate more vigorously [to departments of education], mandatory sexual health education in school curricula" (Health and Welfare Canada, p. ix). There is a 
firm belief that "Effective sexuality education is the cornerstone of primary prevention. Therefore, it is essential that such education be universally available and accessible" (Health and Welfare Canada, p. 34). To achieve the goals of prevention, young people need the information which will allow them to protect themselves from the possibility of negative effects of unprotected sexual activity, but they also need to learn the necessary practical and social skills which will enable them to make use of the information and they need to be able to access counselling and to acquire the contraceptives and prophylactics.

Information and the training of skills to prevent disease and pregnancy are important components in any sex education programme. As well, the ability to apply the knowledge-that is, to use this knowledge to make changes in behaviours, requires discrimination and an acknowledgment of the responsibility for the choices which are made. ${ }^{2}$ Programmes which teach the information and the skills necessary to prevent negative consequences of sexual activity are assumed to be value-free and exclusively empirical, yet they are generally based upon and convey the dominant assumptions which are taken for granted in the society. Empirical knowledge is never the only knowledge which is taught in any sex education course. The selection of facts will always be determined by the interest which guides the inquiry and this will influence the understandings of sexuality-that is, the social knowledge of sexuality which is conveyed through the curriculum. The model of sex education which is a discourse of protection depends upon a biomedical understanding of sexuality and accepts the meanings and the practices which are taken for granted. It does not deal with social and ethical questions, nor does it address issues of power, gender, and relationships.

\section{Speaking of sex}

The meanings about sexuality, or, the social knowledge in a sex education programme, are conveyed through discourse. The identification of discourse names and makes visible some of the assumptions and attitudes which are carried in the ways of speaking about sex and which affect on our lives. The fundamental discourses which reflect a belief in science, individualism, patriarchy, and heterosexism structure our understandings of gender, self, knowledge, sexual orientation, and relationships and they are present in all sex education programs. However, within sex education programmes, particular kinds of discourses also reveal and convey specific attitudes and understandings about sexuality. With a recognition of the discourses, it becomes possible to ask about the implications of the assumptions conveyed through the language. In an important analysis of sex education programmes, Michelle Fine (1988) identified discourses of violence, victimization, and individual morality in sex education programmes which emphasize the danger of sexual relationships, portray women as victims, and advocate a specific morality. These discourses convey negative attitudes about sexuality which not only do not speak to the excitement, interest, hope, and delight that young people feel about their developing sexuality, but they may have negative consequences and result in feelings of fear, shame, or inhibition. Fine pointed out that the lack of credibility of many sex education programmes may be related to the absence of a discourse of desire in them. 
Without an acknowledgment of the role and the force of desire, sex education programmes cannot be related to the students' experiences and the real delight which can be found in sexual relationships. However, desire itself is not unproblematic. Nor is it simple. Desires are sexual but they are not only sexual. Our desires and our goals are shaped within our social context, influenced by what we have experienced and what we have learned. Sexual desire includes desires for sensuous pleasure and for the delight which can be found in body-yours and mine; the emotional and intellectual wish to have relationships with others and to live well, the desire to support and to be supported, to know and be known, to be attracted and to be attractive, to love and to be loved; and, for the possibility these connections have to bring vitality and enengy.

Desire motivates our choices, individual actions, goals, and political decisions. However, our desires may be selfish or base, or they may take others into account, and they may be related to the highest ideals of the culture. The way which we choose between conflicting desires will depend upon their relative strength, upon what we are able to and interested in taking into account as well as upon our goals. The goals we set and the ideals to which we subscribe are very often based on images which have been produced by the media for the marketplace and they need to be subjected to a critical inquiry. However, in the modern western world, the choices which individuals make are regarded as sacrosanct. The unquestioned assumption of the value of individual freedom of choice is a strong cultural belief and it is related to the belief in individualism-the belief that the individual is the most important element in the society. In a study of "the habits of the heart" of Americans, Robert Bellah and others (1985) conclude that the belief in individualism shapes individual lives more than any other influence. The language of individualism idealizes freedom, choice, autonomy, reward for individual effort, independence, and the empowerment and the fulfilment of the individual.

However, our desires do not exist independently of the social context in which we live. Within the discourse of individualism, males and females have different scripts which reflect the patriarchal perspective. Judith Jordan (1987) has examined the way that desire is socialized differently in males and in females during adolescence. She points out that desire-defined as an individual's feeling of wanting to have some experience or object which will satisfy personal needs or physical appetites-is related to the understanding of the self as a separate and independent entity. This corresponds to male desire as it is portrayed in the media where the successful male has exciting and pleasurable experiences as well as power and status. Desire and sexuality are intimately connected and, when desire is understood in this way, "Sexuality then becomes subsumed into a system of achievement, competition, mastery and performance" (Jordan, 1987, p. 13). "The experience of desire typically [becomes] intertwined with the need to control and exert 'mastery' over or 'to own"' (Jordan, 1987, p. 8). The stereotypical understanding of masculine desire and of male sexuality which emphasizes conquest and individual performance and which does not acknowledge the need for emotional intimacy is supported by male banter and by images in the media and in pornographic materials. The language of privilege, rights, power and control, separation, competition, domination, and subordination contains the seeds of violence. 
Women often experience desire in the context of a relationship with another. The interest in closeness, tenderness, emotional intimacy, and being loved by and connected with another is common in the female experience of desire. Women's concern for relationship and the assumption of a responsibility for the emotional work in intimate relationships is promoted by the romantic discourse which holds out the promise that, when he is strong and handsome and she is beautiful and lovable, they can live "happily ever after." The message that a female should accommodate another's wishes is reinforced heavily in adolescence, but when accommodation meets entitlement, the accommodating person may feel invalidated.

Yet, the realization that young women need to be freed from the assumption of a stereotypical feminine role in sexual behaviour does not necessarily mean that women ought to appropriate masculine stereotypical behaviours. A stereotypical masculine understanding of egocentric desire and of sexual relationships is also fundamentally deficient as a model for human relationships. A freedom for sexual license without a concern for relationship is a freedom that many find unsatisfying. Any ongoing and mutually satisfying relationship depends upon the individuals involved being willing and being able to attend to and to enjoy both the self and the other in the context of the relationship. It is useful to point out that just as females are not lacking in desire for personal sexual fulfilment, males are not lacking in concern for relationship, but the stereotypical understanding of masculine desire and the construction of male sexuality, which is learned informally through the ongoing cultural discourse, separates the sexual relationship from a romantic relationship, while sex and romance are conflated in the construction of feminine sexuality. Neither the separation of sex and emotional connection nor demand for a conflation of sex and a particular quality of emotion allows a useful exploration of the connection between these two forces in sexual relationships. The association of each of these two different approaches with a specific gender leads to much misunderstanding. But by openly exploring the true nature of their desire in relationship and sharing interest in the presence of the other, there is some possibility for both men and women to come to know their own wholeness.

The romantic discourse, which is shaped by the assumptions of our patriarchal and individualistic society, speaks almost exclusively about heterosexual relationships. It is a major factor in the informal sex education, especially of young women. It influences our desires and our beliefs about ourselves and others, and our understandings of gender, sexuality and human possibility.

\section{Directions}

The feminist critique and the critique of normative heterosexism have raised important questions about the assumptions we have made about our social and sexual relationships and about the negative impact of these assumptions. The formal curriculum of any educational programme needs to incorporate the understandings which have been gained by the analyses of the way gender has been understood and of the homophobia resulting from the identification of homosexuality as abnormal or sinful. In order to be free of the past so that we might be free to take responsibility for the future, both teachers and students need to become engaged in a critical inquiry about sexuality. The curriculum of 
the sex education programme becomes a critical inquiry when the understandings of gender and of sexual relationships which are predominant in the society and are carried in the formal and the informal curriculum are reflected upon.

The educational challenge "to press students to [question] and reframe their own, as well as others', constructed meanings" (Phillips \& Fine, 1992, p. 248), accept the responsibility of their own human autonomy, and understand the complexity of social interactions encourages them to become critical knowers. This undertaking necessitates an evaluation of our present social situation and points to the need to understand alternatives and to take responsibility for the choices we make and it requires that educators engage in this inquiry as well. Evaluation and choice depend upon ethical considerations.

Educators have to address questions of ethics in two different ways-in making educational decisions about policy and curriculum, for example, and in developing the students' ability to make choices wisely. How students can be made aware of the fact that they are ethical decision makers and that it makes a difference - that is, that they are responsible-and how they can be helped to become wiser, more compassionate, and more courageous members of the society are different questions from those about what kind of values are carried in the programmes. The development of ethical knowledge is a development of care for others and of a sense of justice. The growth of these is a result of an increasing recognition of the importance of our relationships with others. The perspective which understands the need for the development of care and a concern for individual and social justice does not name particular acts as moral or immoral, but points to the need for an ongoing, open-minded, reflective evaluation of actions in the context of our social relationships in the broadest sense.

The recognition of the requirement to address empirical, social, and cultural questions, and critical and ethical concerns within a sex education programme points to the need of a comprehensive sexuality education. A comprehensive sexuality curriculum must be based upon the understandings and the experiences of the students and teachers for this is the material which needs to be examined and reflected upon and to be changed or augmented. A critical, reflective inquiry about sexuality and about the ways we have individually and culturally responded to questions about sexuality constitutes the method of a critically-based sexuality curriculum. This inquiry needs to take place within the various subject areas across the curriculum. The processes of growth, reproduction, and disease transmission and how to avoid negative consequences of sexual behaviours are important for students know about, but biology is not the only subject in which sexuality can be studied. A study of literature and the media can show a range of understandings of sexuality and the implications of these can be explored. Through an investigation of social and political decisions which have been made and their relation to our lives and to understandings of sexuality, we can raise questions about the kinds of issues which we need to address. Reproductive technology, policy about abortion, discrimination against homosexuals, and the impact of the social changes, including the changing identity of the family, upon children are some of the issues which need to be carefully considered by the electorate. The relationships between pornography and sexual violence, sexual harassment and sexual violence, and violence and the alienation experienced by many people need to be explored for these are the areas about which citizens are expected to make decisions. 
Case studies which reveal the complexity of some of the issues involved, a comparative study of the understandings of gender and sexuality and the different responses to these in different cultures, and a critical inquiry into the way that the media shapes our lives can enlarge the perspective of each of the students. It is important for educators to develop students' critical ability and ethical capability so that they will become able to take responsibility for their personal and political decisions. The exploration of difficult and sometimes controversial issues provides students with a chance to develop their understandings of the social, political, and cultural roots of our beliefs and practices, and of the implications of our choices for ourselves and for others. An examination of these kinds of issues, which do not have easy solutions but which require thoughtful and careful response, promotes the development of critical and ethical knowing.

The point of such a conversation is not always to reach a consensus, nor is it to determine which point of view is better, but rather it is found in the exchange and in the opportunity to enlarge our understanding of complex issues and to become more deeply aware of our own and each others' lives. The teacher's role in this is a demanding one for it requires being part of the process at the same time as watching over and guiding the process so that the students and teacher can identify and challenge the assumptions which rule and so that students can gain the knowledge that can empower them for responsible decision making as individuals and as members of a society.

A reflective inquiry about sexuality can free students from conclusions reached or patterns of behaviour established as a result of particular experiences in the past. As well, an exchange with others about issues which are related to the real concerns we have as individuals or as a society can enlarge their understanding of the human situation. It can foster compassion and it can prepare students for the kinds of questions they may face in their lives. Ideally, sex education will change the lives of the students for the better so that they might be healthier, happier, freer, more loving, and more joyous in their lives as male or as female and in their relationships with others, who are male and female, than if they had not taken the course. Otherwise, why bother?

Issues of sexuality do not only arise in health and sex education classes. As James Whitson (1992) has pointed out, since our social reality is inextricably connected with sexuality, sexuality cannot be eliminated from our curriculum of cultural studies and liberal arts. Sex education teachers can and should make use of the material from other areas in the curriculum as well as the material in the informal curriculum. However, a corollary of the fact that our social reality is related to our sexual reality is that every teacher is a teacher of sex education. Sexuality is a topic of the formal and of the hidden curriculum in every subject. Understandings of gender and of sexuality are conveyed and learned in every area of the curriculum-in literature, history, biology, family studies, economics, political science, and religious studies, as examples, through the content of the material which is studied and through the attitudes of the teacher and students who interpret that material. This realization has pedagogical implications for pre-service and in-service programmes for the question "What do we know and what do we need to know about sex?"' is relevant for all teachers. 
Finding a response to the question "What is a good sex life?" depends upon and develops the empirical, social, critical, and ethical knowledge about sexuality of the teachers and the students. The point of such an inquiry is not to establish definitive answers for everyone, but it is to deepen the question so that we may come to understand the world and ourselves more fully as we engage with the question: "What is a good life?"

\section{Notes}

${ }^{1}$ The use of the pronoun "we" is ambiguous unless it is specified or made clear within a particular context. The reference depends upon who is speaking and upon the purpose of the reference. It is valuable because it personalizes the discussion for the reader by referring to the writer and may include the reader. However, it is useful to remember that the ambiguity may mask the diversity within any group. Every group contains a wide variety of individuals within it. Or, it may conceal an attempt to make others like myself. The question "What do we need to know?" may sometimes mean "What do I think they need to know?"'

${ }^{2}$ The programme "Skills for Healthy Relationships" was developed in response to the recognition of the needs to help youth protect themselves from sexually transmitted disease and emphasizes the acquisition of knowledge and the development of the required skills which include learning helpful scripts and of the value being assertive.

\section{Bibliography}

Bellah, R., Madsen, R., Sullivan, W., Swidler, A. \& Tipton, S. (1985). Habits of the Heart. New York: Harper \& Row.

Bibby, R. \& Posterski, D. (1992). Teen Trends: A Nation in Motion. Toronto: Stoddard Publishing.

Fine, M. (1988). "Sexuality, Schooling, and Adolescent Females: The Missing Discourse of Desire." Harvard Educational Review, 58(1), 29-53.

Fisher, W.A. (1990a). "Understanding and Preventing Adolescent Pregnancy and Sexually Transmitted Disease." J. Edwards et al. (eds.), Social Influence Processes and Prevention. New York: Plenum Press. 71-101.

Fisher, W.A. (1990b). "All Together Now: An Integrated Approach to Preventing Adolescent Pregnancy and STD/HIV Infection." SIECUS Report, 18(4), 1-11.

Forrest, J. \& Silverman, J. (1989). "What Public School Teachers Teach about Preventing Pregnancy, AIDS and Sexually Transmitted Diseases." Family Planning Perspectives, 21(2), 65-72.

Health Canada (1994). Skills for Healthy Relationships. Ottawa: Canadian Public Health Association.

Health Canada (1994). Canadian Guidelines for Sexual Health Education. Ottawa: Health Services Systems Division.

Health and Welfare Canada (1990). Report on Adolescent Reproductive Health. Ottawa: Health Services and Promotion Branch. 
Hudson, B. (1984). "Femininity and Adolescence." In A. McRobbie \& M. Nava (eds.), Gender and Generation. London: Macmillan. 31-53.

Jordan, J. (1987). "Clarity in Connection: Empathic Knowing, Desire and Sexuality." Stone Centre Working Paper Series. Work in Progress, Number 29. Wellesley, MA.

King, A. et al. (1989). Canada Youth and AIDS Study. Ottawa, ON: Health and Welfare Canada.

Lieberman, M. (1992). “"Some Day My Prince Will Come': Female Acculturation Through the Fairy Tale." In M. Schaum \& C. Flanagan (eds.), Gender Images. Boston: Houghton Mifflin. 247-261.

Mercer, S. (1988). "Not a Pretty Picture: An Exploratory Study of Violence Against Women in High School Dating Relationships." Resources for Feminist Research, 17(2), 15-23.

Murray, P. (1991). "Scientific Knowledge and Spiritual Understanding." In R. Ravindra (ed.), Science and Spirit. New York: Paragon. 251-265.

Murray, P. (1989). "Sex Education: A Discourse of Sexuality." McGill Journal of Education, 24(3), 321-330.

Phillips, L. \& Fine, M. (1992). “Commentary: What's "Left" in Sexuality Education?" In J. Sears (ed.), Sexuality and the Curriculum. New York: Teachers College Press. 242-250.

Trudell, B. (1992). "Inside a Ninth-Grade Sexuality Classroom: The Process of Knowledge Construction." In J. Sears (ed.), Sexuality and the Curriculum, op. cit., 203-225.

Vance, C. (1989). "Pleasure and Danger: Toward a Politics of Sexuality." In C. Vance (ed.), Pleasure and Danger: Exploring Female Sexuality. London: Pandora. 1-28.

Weeks, J. (1986). Sexuality. Chichester: Ellis Horwood.

Whatley, M. (1987). "Goals for Sex Equitable Sexuality Education." Peabody Journal of Education, 64(4), 59-70.

Whatley, M. (1988) "Raging Hormones and Powerful Cars: The Construction of Men's Sexuality in School Sex Education and Popular Adolescent Films." Journal of Education, 170(3), 100-121.

Whatley, M. (1992). "Commentary: Whose Sexuality Is It Anyway?'” In J. Sears (ed.), Sexuality and the Curriculum, op. cit., 78-84.

Whitson. J. (1992). "Sexuality and Censorship in the Curriculum: Beyond Formalistic Legal Analysis." In J. Sears (ed.), Sexuality and the Curriculum, op. cit., 59-77. 